\title{
Passive Robustness Computing of a Milk Manufacturing Unit with Time Constraints: Alarm Filtering Issues
}

\author{
Simon COLLART DUTILLEUL ${ }^{1}$, Anis M'HALLA ${ }^{1,2}$, Etienne CRAYE ${ }^{1}$, Mohamed BENREJEB ${ }^{2}$ \\ ${ }^{1}$ Laboratoire d'Automatique, Génie Informatique et Signal, \\ Ecole Centrale de Lille, \\ Cité Scientifique BP 48, \\ 59651 Villeneuve d'Ascq, France, \\ simon.collart_dutilleul@ec-lille.fr, anis.mhalla@enim.rnu.tn, etienne.craye@ec-lille.fr \\ ${ }^{2}$ Laboratoire de Recherche en Automatique, \\ Ecole Nationale d'Ingénieurs de Tunis, \\ BP 37, le Belvédère, 1002 Tunis, Tunisie, \\ mohamed.benrejeb@enit.rnu.tn
}

\begin{abstract}
The presented work is dedicated to the robustness of a milk manufacturing workshop including time interval constraints. In such systems, operation times are included between a minimum and a maximum value. Weighted Marked Graphs are used for modelling. Some results proposing to transform Weighted Marked Graphs into Marked Graphs are reviewed, which allow obtaining a model that can be used to apply some robustness results of the state of the art. The main contribution of this paper is a computing algorithm of the maximal time disturbances allowed at a given point. Finally, to demonstrate the effectiveness and accuracy of the proposed algorithm, an application to a milk production unit is outlined. The possession of this exact value allows checking the death of marks on the levels of synchronization transitions of a P-time Petri net model without generating any false alarm. . The results show that the difference between the exact value and the lower bound of the state of the art algorithm is quite important.
\end{abstract}

Keywords: Weighted Marked Graphs, P-time Petri nets, milk manufacturing unit, passive robustness, false alarm, time disturbance.

\section{Introduction}

Many techniques for the modeling and quantitative analysis of manufacturing systems have been investigated. Among them, Coloured Petri Nets are considered as tools especially suitable for systems that exhibit concurrency, conflicts, and synchronization. Unfortunately, when there are maximum duration constraints, the modelling power of Coloured Petri Net is a disadvantage, as it becomes really difficult to prove, using properties of the net structures that the time constraints remains fulfilled.

Marked Graphs (MG) on the other hand are known for their strong analytical properties, but they do not allow the assembly or disassembly of batch components to be represented in a compact form. To take into account these kinds of processes and to reduce the size of the models, Weighted Marked Graphs (WMGs) can be used [Toursi and Sauer, 2004], [Marchetti and Munier, 2009]. WMGs are particular MGs allowing weights on the arcs. In most works, the proposed solution is to transform the WMG into an ordinary MG allowing the use of well-known methods of performances analysis [Munier, 1993], [Nakamura and Silva, 1999], [Hamaci et al., 2006]. Marked Graphs indeed are specifically designed to do performance evaluations which prove some structural properties on the graphs. However, few results based upon this tool address the time disturbance robustness problem.

The systems considered with these approaches have a robustness property which allows maintaining products quality when there are time disturbances [Jerbi et al., 09]. The robustness is defined as the ability of the system to preserve the specifications facing some expected or unexpected variations. Therefore, the robustness characterizes the capacity to deal with disturbances. Passive robustness is based upon variations included in validity time intervals. There is no control modification to preserve the required specifications.

The work presented in this paper focuses on the robustness of workshops with assembling tasks, regarding time disturbances. This paper is organised as follows. Section 2 begins with the definition of the P-time Petri Nets and WMGs models of workshops. In section 3 , some results about the transformation of a WMG into an ordinary MG are described. They can be used as a first step towards the study of the robustness of the considered milk manufacturing unit.

The problem of the passive robustness of manufacturing systems is tackled in section 4 . The passive robustness (local robustness) of a 
given path in the milk manufacturing workshop is analytically built up. Lastly, a new algorithm computing the exact passive robustness margin allowed at a given node is presented. An illustrative example is outlined and the qualitative results are discussed. Finally, some conclusions of this work are given.

\section{Modelling}

In this section we recall the basic concepts and notations that are going to be used.

\subsection{P- time Petri net}

Definition 1 [Khansa et al., 96]: The formal definition of a P-time Petri Net (Rp) is given by a pair $<\mathrm{R}$; IS $>$, where:

- $\mathrm{R}$ is a marked Petri net,

- IS: $\mathrm{P} \rightarrow Q^{+} \times\left(Q^{+} \cup\{+\infty\}\right)$ pi $\rightarrow$ ISi $=$ [ai, bi] with $0 \leq$ ai $\leq$ bi.

${ } S_{i}$ defines the static interval of staying time of a mark in the place $\mathrm{p}_{\mathrm{i}}\left(Q^{+}\right.$is the set of positive rational numbers). A mark in the place $p_{i}$ is taken into account in transition validation when it has stayed in $\mathrm{p}_{\mathrm{i}}$ for at least a duration $\mathrm{a}_{\mathrm{i}}$ and no longer than $b_{i}$. After the duration $b_{i}$ the token will be dead.

Let us denote by:

- $\mathrm{q}_{\mathrm{ie}}$ : the expected sojourn time of the token in the place $\mathrm{p}_{\mathrm{i}}$,

- $t_{i}$ (resp. $t{ }_{i}$ ): the output places of the transition $t_{i}$ (resp. the input places of the transition $\mathrm{t}_{\mathrm{i}}$ ),

- $\mathrm{p}_{\mathrm{i}}$ (resp. $\mathrm{p}_{\mathrm{i}}$ ): the output transitions of the place $\mathrm{p}_{\mathrm{i}}$ (resp. the input transitions of the place $\mathrm{p}_{\mathrm{i}}$ ),

- $\mathrm{St}_{\mathrm{e}}(\mathrm{n})$ : the $\mathrm{n}^{\mathrm{nd}}$ expected firing instant of the transition $\mathrm{t}$,

- St(n): the $\mathrm{n}^{\text {nd }}$ effective firing instant of the transition $\mathrm{t}$,

- G: the P-time Petri net model of the workshop,

- IN(Lp): the first node of the path Lp,

- OUT(Lp): the last node of the path Lp,

- $T_{S}$ : the set of synchronization transitions,

- $\quad T_{P}$ : the set of parallelism transitions.

\subsection{Weighted marked graph}

To model complex dynamic systems and to reduce the size of the model, WMGs can be used [Sauer, 03].

Definition 2 [Commoner et al., 71]: A MG (also called event graph) is a Petri net such that each place has exactly one input and one output transition and the weight associated to each arc is equal to 1 .

Definition 3 [Commoner et al., 71]: A WMG (also called weighted T-graph or weighted event graph) is a MG such that the weight associated to each arc is a non negative integer number.

\subsection{Presentation of the workshop}

Figure 1 shows a milk manufacturing unit in repetitive functioning mode, composed by six machines $\left(M_{1}, M_{2}, M_{3}, M_{4}, M_{5}, M_{6}\right)$ and seven conveyors $\left(T_{1}, T_{2}, T_{3}, T_{4}, T_{5}, T_{6}, T_{7}\right)$, where:

$-\mathrm{M}_{1}$ is a bottle filling machine,

$-\mathrm{M}_{2}$ is a milk bottle capper,

- $\mathrm{M}_{3}$ is a time/date stamp,

$-\mathrm{M}_{4}$ is a hydromat,

$-\mathrm{M}_{5}$ is a labelling machine,

$-\mathrm{M}_{6}$ is a packaging machine.

To manufacture the product (bottles of 1000 $\mathrm{ml}$ ), empty bottles (by group of 6) are placed on the conveyor $\mathrm{T} 1$ to supply the bottle filling machine M1. Once this operation is completed, the filled bottles are transported towards the capping machine M2 by the conveyor T2. After capping, the bottles arrive directly on T3; this conveyor carries the bottles to the machine M3 (time/date stamp) to print the manufacturing date and end date of consumption.

The bottles leave the machine M3 on a conveyer T4 towards the machine M4 (Hydromat). The hydromat ensures the milk sterilization: the milk is heated to sterilization temperature of $140^{\circ}-150^{\circ} \mathrm{C}$. After sterilization, cooling takes place using a cold water tank and atmospheric air. As a result, the milk does not require refrigeration and has a relatively longer shelf life (3 to 6 months at ambient temperature) with an excellent safeguarding of the vitamins and original qualities. Once this task is completed, the bottles are transferred to the labelling machine M5 via the conveyor T5. After, the bottles arrive to the packaging machine M6, where they will be wrapped by 
welding in a group of 6. Lastly, the finished product is deposited on the conveyor T7 towards the stock of finished products SA.

$\left.\mathrm{p}_{8}, \mathrm{p}_{10}, \mathrm{p}_{12}, \mathrm{p}_{14}\right\}$ and $\mathrm{R}_{\mathrm{N}}=\left\{\mathrm{p}_{1}, \mathrm{p}_{15}, \mathrm{p}_{16}, \mathrm{p}_{17}, \mathrm{p}_{18}\right.$, $\left.\mathrm{p}_{19}, \mathrm{p}_{20}\right\}$.

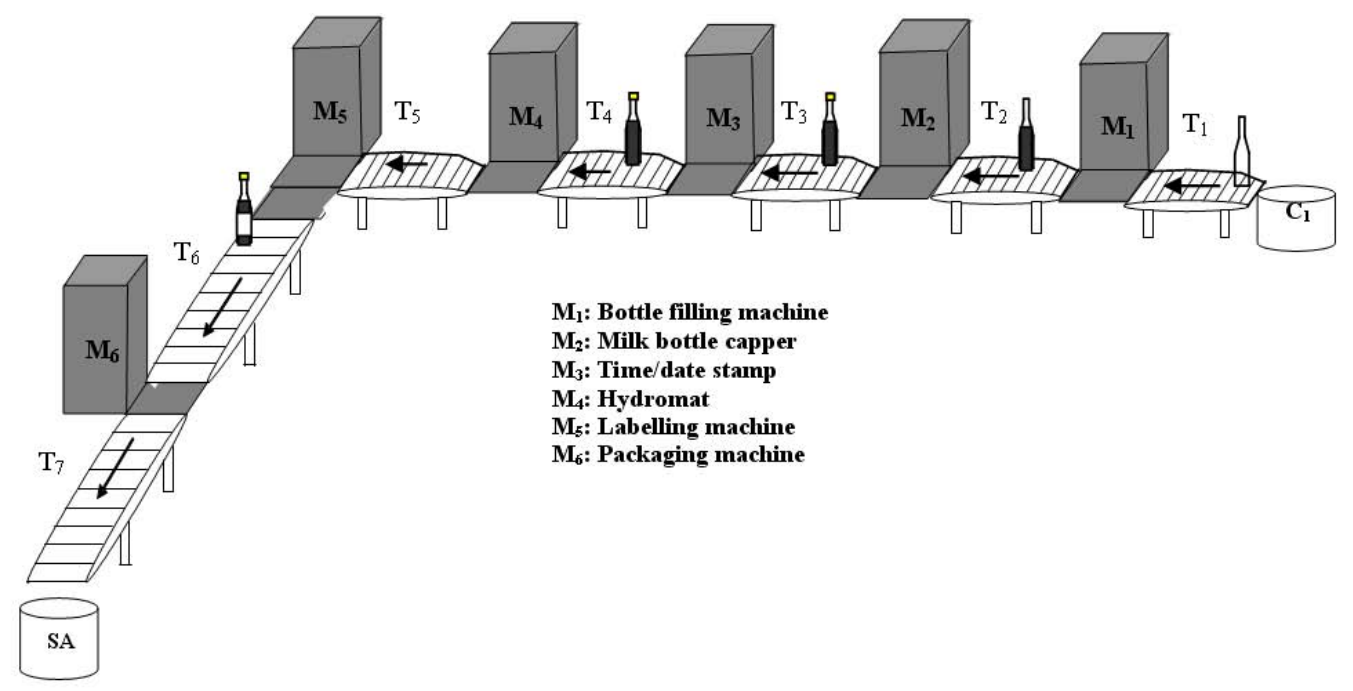

Figure 1. Milk manufacturing unit

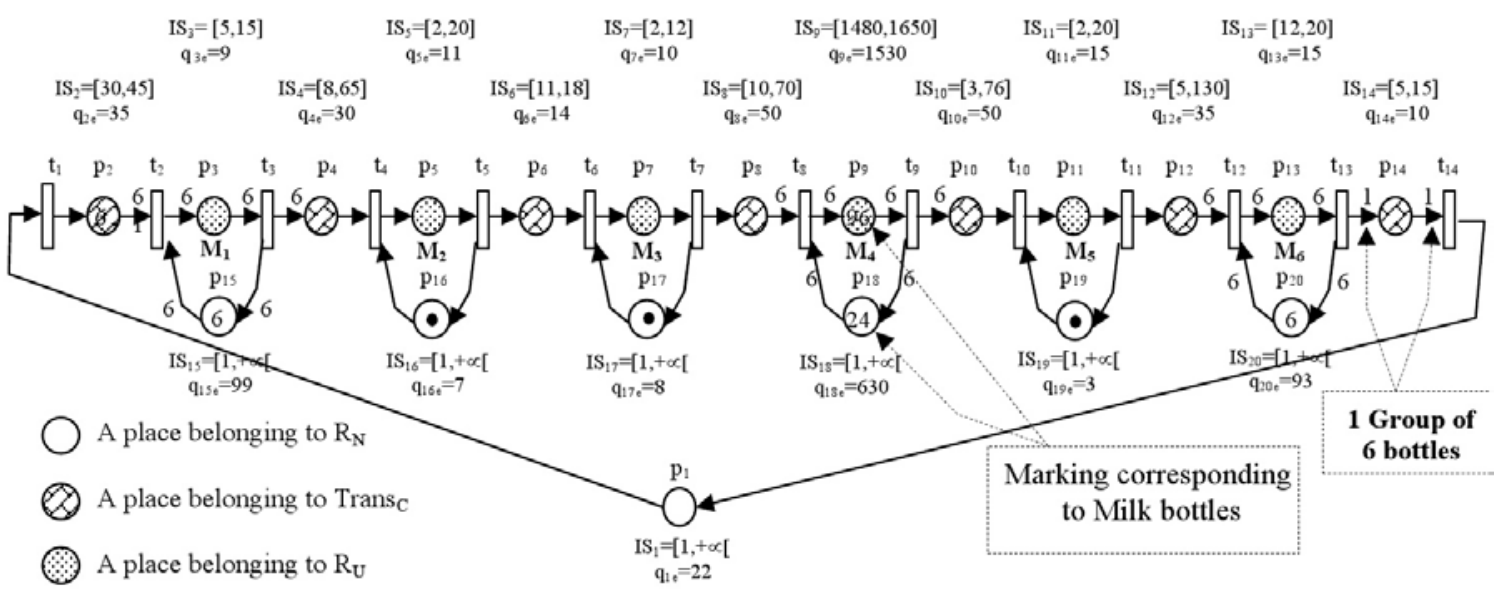

Figure 2. A Milk manufacturing unit modeled by a WMG

\subsection{Functional decomposition}

As the sojourn times in places have not the same functional signification when they are included in the sequential process of a product or when they are associated to a free resource, a decomposition of the Petri net model into three sets is made using [Long, 93]:

- $R_{U}$ is the set of places representing the used machines,

- Trans $_{C}$ is the set of places representing the loaded transport resources,

- $\mathrm{R}_{\mathrm{N}}$ corresponds to the set of places representing the free machines

Figure 2 shows a weighted event graph modeling a milk production workshop where: $\mathrm{R}_{\mathrm{U}}=\left\{\mathrm{p}_{3}, \mathrm{p}_{5}, \mathrm{p}_{7}, \mathrm{p}_{9}, \mathrm{p}_{11}, \mathrm{p}_{13}\right\}$, Trans $_{\mathrm{C}}=\left\{\mathrm{p}_{2}, \mathrm{p}_{4}, \mathrm{p}_{6}\right.$,

\section{Weighted Marked Graph System Transformation}

\subsection{State of the art overview}

In [Munier, 1993] the initial WMG is the object of an operation of expansion. Unfortunately, this expansion can lead to a model of significant size, which does not depend only on the initial structure of the WMG, but also on the initial marking. With this method, the system transformation proposed under single server semantics hypothesis, or in [Nakamura and Silva, 1999] under infinite server semantics hypothesis, leads to a WMG with $|\theta|$ transitions $(|\theta|$ is the 1-norm of the elementary T-semiflow of the corresponding WMG). Inspired by this work, a linearization method without increasing 
the number of transition was proposed in [Hamaci et al., 2006] by using (min, +) algebra.

\subsection{Transformation of WMG associated to milk manufacturing unit}

Based on the transformation algorithm given in

[Nakamura and Silva, 1999], a systematic transformation from the WMG system into a MG system is done, Fig. 3. A more detailed description of this approach is given in [M'halla et al., $10 \mathrm{~d}$ ]. The obtained MG is used to study the passive robustness of the milk manufacturing workshop.

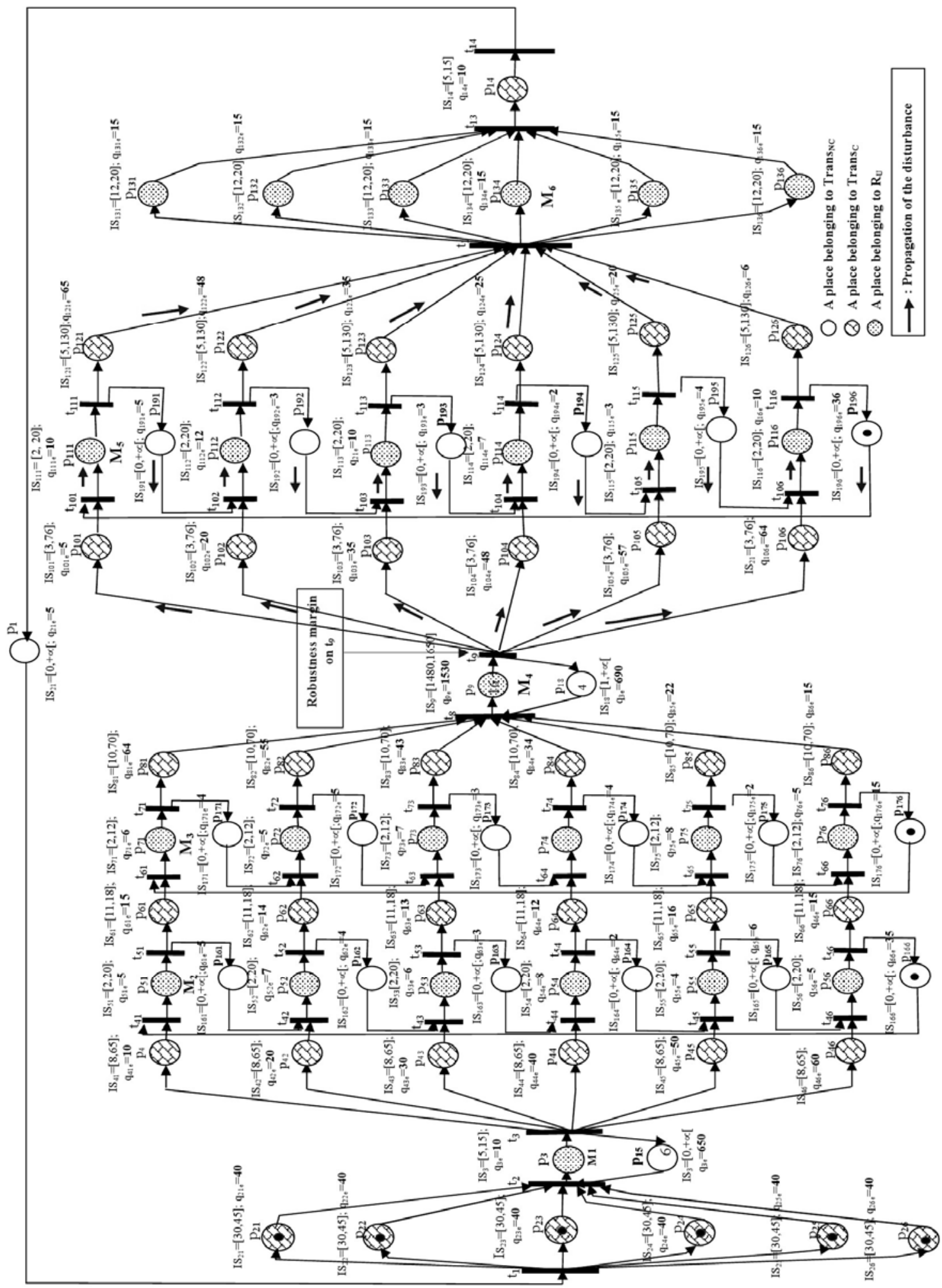

Figure 3. A milk manufacturing unit modeled by a P-time Petri net 


\section{Passive Robustness}

In milk a manufacturing workshop a time interval is associated to each operation. Its lower bound indicates the minimum time needed to correctly execute the operation. The upper bound sets the maximum time not to be exceed otherwise the quality of the product is deteriorated.

In the category of workshops which is studied in this paper, the operations have temporal constraints. The violation of these constraints may have a dramatic and bad impact on the health of consumers. Thus, the detection of constraint violations automatically causes the stop of the production. Then dangerous products (an overheating of milk bottles in a hydromat for example) are put away. On the considered workshop topology, this scenario is really critical, because of assembling tasks.

When the system behaviour remains in the system robustness ranges, it is proven that a violation of constraints did not take place. In this case, we plan to keep on producing and the production is said to be in degraded mode. Of course, the products are not degraded, but the production mode is degraded because the delivery moments of the products are not the ones which have been planned. It this context, we detail two algorithms for passive robustness interval computing. The first one has been already presented [M'halla et al., 10c], but the second one is new.

\subsection{Basic definition}

Definition 4: Let us consider a discrete event system and $G$ the associated Petri net model. Let us call $B(G)$ the behaviour of $G$ corresponding to the trajectory of states successively reached. Let $C(B(G))$ be the schedule of conditions established on the system behaviour $B(G) . \quad C(B(G))$ is materialized by a series of constraints which must be checked by $B(G)$. A non respect of $B(G)$ corresponds to a violation of $C(B(G))$. It is said that a subset $S G$ of $G$ is robust to a disturbance $\delta$ if and only if $\forall \mathrm{n} \in \mathrm{SG}$, the occurrence of the disturbance $\delta$ at the node $n$ does not involve a violation of $\mathrm{C}(\mathrm{B}(\mathrm{G})$ ).

Definition 5 [Collart Dutilleul et al., 07]: A system is said to have passive robustness when no control changes are necessary to preserve the specified properties when there are variations.
Definition 6 [Jerbi et al., 04]: It is said that a path $L p$ has a local passive robustness on $\left[\delta_{\min }\right.$, $\left.\delta_{\max }\right]$ if the occurrence of a disturbance $\delta \in\left[\delta_{\min }\right.$, $\left.\delta_{\max }\right]$ at any place $\mathrm{p} \in \mathrm{Lp}$ does not involve a token death at the synchronization transition of Lp.

Definition 7 [Jerbi et al., 04]: A monosynchronized subpath Lp is a path containing one and only one synchronization which is its last node.

Definition 8 [Jerbi et al., 09]: An elementary mono-synchronized subpath is a monosynchronized subpath beginning with a place $p$ such as ${ }^{\circ} \mathrm{p}$ is a synchronization transition.

Figure 4 shows an elementary monosynchronized subpath $\mathrm{Lp}_{7}=\left(\mathrm{p}_{111}, \mathrm{t}_{111}, \mathrm{p}_{191}, \mathrm{t}_{102}\right)$ with different notations.

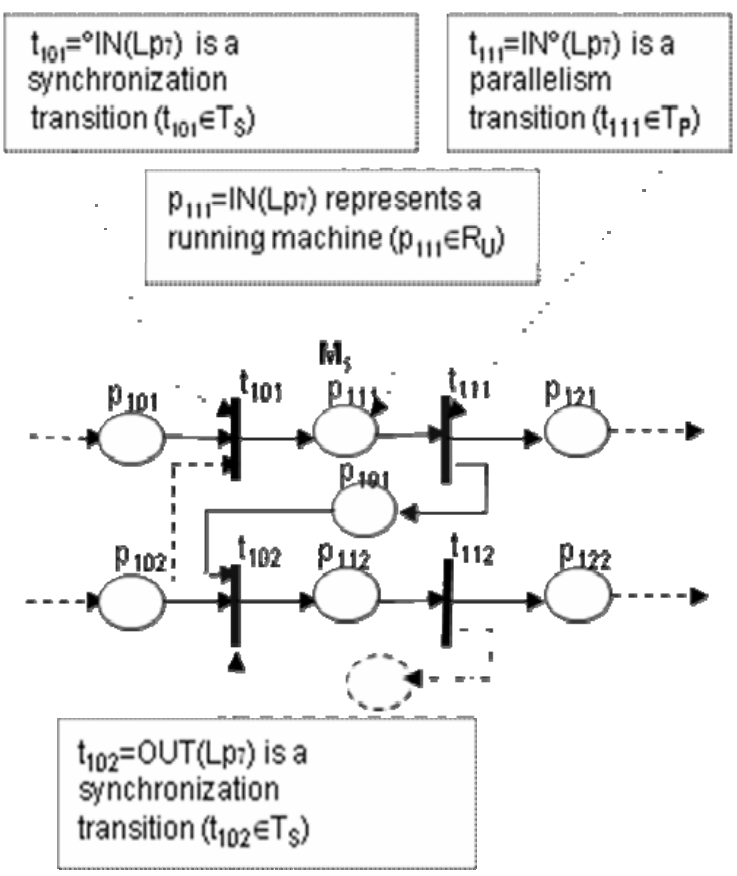

Figure 4. An Elementary Mono-Synchronized Subpath

Definition 9 [Jerbi et al., 09]: The time passive rejection capacity interval of a path $L p$ is $\mathrm{RC}(\mathrm{Lp})=[\mathrm{Ca}(\mathrm{Lp}), \mathrm{Cr}(\mathrm{Lp})]$ where:

$$
\begin{aligned}
& \mathrm{Ca}(\mathrm{Lp})=\sum_{\mathrm{p}_{\mathrm{i}} \in \mathrm{Lp} \cap\left(\mathrm{R}_{\mathrm{N}} \cup \operatorname{Trans}_{\mathrm{NC}}\right)}\left(\mathrm{q}_{\mathrm{ie}}-\mathrm{b}_{\mathrm{i}}\right), \\
& \operatorname{Cr}(\mathrm{Lp})=\sum_{\mathrm{P}_{\mathrm{i}} \in \mathrm{Lp} \cap\left(\mathrm{R}_{\mathrm{N}} \cup \text { Trans }_{\mathrm{NC}}\right)}\left(\mathrm{q}_{\mathrm{ie}}-\mathrm{a}_{\mathrm{i}}\right) .
\end{aligned}
$$

\subsection{Passive Robustness computation}

To compute the local passive robustness interval, the concepts of compensable and transmissible margin are introduced. Let us 
denote by: $\Delta \mathrm{rc}_{\mathrm{k}}$ and $\Delta \mathrm{rt}_{\mathrm{k}}$ respectively the compensable margin and the transmissible margin on the mono-synchronized subpath $\mathrm{Lp}_{\mathrm{k}}$. The local passive robustness delay $\Delta \mathrm{r}_{\mathrm{Lpk}}$ can be calculated using formulas (3), (4) and (5) [Jerbi et al., 09].

$$
\Delta \mathrm{r}_{\mathrm{Lp}_{\mathrm{k}}}=\Delta \mathrm{rc}_{\mathrm{k}}+\Delta \mathrm{rt}_{\mathrm{k}}
$$

With:

$$
\begin{gathered}
\Delta \mathrm{rc}_{\mathrm{k}}=\sum_{\mathrm{p}_{\mathrm{i}} \in \mathrm{Lp}_{\mathrm{k}} \cap\left(\mathrm{R}_{\mathrm{N}} \cup \operatorname{Trans}_{\mathrm{NC}}\right)}\left(\mathrm{q}_{\mathrm{ie}}-\mathrm{a}_{\mathrm{i}}\right) \\
\Delta \mathrm{rt}_{\mathrm{k}}=\underset{\min \left(\mathrm{b}_{\mathrm{i}}-\mathrm{q}_{\mathrm{ie}}\right)}{\mathrm{p}_{\mathrm{i}}^{\mathrm{o}}=\operatorname{OUT}\left(\mathrm{Lp}_{\mathrm{k}}\right)} \\
\mathrm{p}_{\mathrm{i}} \notin \mathrm{Lp} \mathrm{p}_{\mathrm{k}}
\end{gathered}
$$

In Table 1, we can quote the following examples of the compensable margin and the transmissible margin associated to some monosynchronized subpath $L p_{k}$ of the P-time Petri net model (Figure. 3).

Table 1. Compensable margin and transmissible margin

\begin{tabular}{|l|c|c|}
\hline \multicolumn{1}{|c|}{ Path } & $\Delta \mathrm{rt}_{\mathrm{k}}$ & $\Delta \mathrm{rc}_{\mathrm{k}}$ \\
\hline $\mathrm{Lp}_{0}=\left(\mathrm{p}_{9}, \mathrm{t}_{9}, \mathrm{p}_{18}, \mathrm{t}_{8}\right)$ & 6 & 689 \\
\hline $\mathrm{Lp}_{1}=\left(\mathrm{p}_{9}, \mathrm{t}_{9}, \mathrm{p}_{101}, \mathrm{t}_{101}\right)$ & $+\infty$ & 0 \\
\hline $\mathrm{Lp}_{2}=\left(\mathrm{p}_{9}, \mathrm{t}_{9}, \mathrm{p}_{102}, \mathrm{t}_{102}\right)$ & $+\infty$ & 0 \\
\hline $\mathrm{Lp}_{3}=\left(\mathrm{p}_{9}, \mathrm{t}_{9}, \mathrm{p}_{103}, \mathrm{t}_{103}\right)$ & $+\infty$ & 0 \\
\hline $\mathrm{Lp}_{4}=\left(\mathrm{p}_{9}, \mathrm{t}_{9}, \mathrm{p}_{104}, \mathrm{t}_{104}\right)$ & $+\infty$ & 0 \\
\hline $\mathrm{Lp}_{5}=\left(\mathrm{p}_{9}, \mathrm{t}_{9}, \mathrm{p}_{105}, \mathrm{t}_{105}\right)$ & $+\infty$ & 0 \\
\hline $\mathrm{Lp}_{6}=\left(\mathrm{p}_{9}, \mathrm{t}_{9}, \mathrm{p}_{106}, \mathrm{t}_{106}\right)$ & $+\infty$ & 0 \\
\hline $\mathrm{Lp} \mathrm{p}_{7}=\left(\mathrm{p}_{111}, \mathrm{t}_{111}, \mathrm{p}_{191}, \mathrm{t}_{102}\right)$ & 56 & 5 \\
\hline $\mathrm{Lp} \mathrm{p}_{8}=\left(\mathrm{p}_{112}, \mathrm{t}_{112}, \mathrm{p}_{192}, \mathrm{t}_{103}\right)$ & 41 & 3 \\
\hline $\mathrm{Lp} \mathrm{p}_{9}=\left(\mathrm{p}_{113}, \mathrm{t}_{113}, \mathrm{p}_{193}, \mathrm{t}_{104}\right)$ & 28 & 3 \\
\hline $\mathrm{Lp}_{10}=\left(\mathrm{p}_{114}, \mathrm{t}_{114}, \mathrm{p}_{194}, \mathrm{t}_{105}\right)$ & 19 & 2 \\
\hline $\mathrm{Lp}_{11}=\left(\mathrm{p}_{115}, \mathrm{t}_{115}, \mathrm{p}_{195}, \mathrm{t}_{106}\right)$ & 12 & 4 \\
\hline $\mathrm{Lp}_{12}=\left(\mathrm{p}_{116}, \mathrm{t}_{116}, \mathrm{p}_{196}, \mathrm{t}_{101}\right)$ & 71 & 36 \\
\hline $\mathrm{Lp} \mathrm{p}_{13}=\left(\mathrm{p}_{71}, \mathrm{t}_{71}, \mathrm{p}_{81}, \mathrm{t}_{8}\right)$ & 15 & 0 \\
\hline
\end{tabular}

\subsubsection{Computation algorithms of passive robustness for a delay}

In this section, two algorithms for building, respectively, a lower bound and the exact maximum value of the passive robustness margin are presented. The computing algorithm of the exact maximal time disturbance allowed at a given point is an important contribution of this paper. A comparative study between the two algorithms is then developed.

\subsubsection{Computation algorithm of a lower bound of passive robustness delay}

In order to detect the constraint violation, the presented algorithm [Jerbi et al, 04] computes a lower bound of the maximal time disturbance allowed at a given node $n$.

It involves:

- Selecting the node where we want to calculate the passive robustness margin,

- Building the set of mono-synchronized subpaths $(\varphi)$ defined as follows: $\varphi=\left\{\mathrm{Lp}_{\mathrm{j}} /\left(\mathrm{n}^{\circ}=\mathrm{IN}\left(\mathrm{Lp}_{\mathrm{j}}\right)\right) \wedge\left(\mathrm{Lp}_{\mathrm{j}} \in \mathrm{C}_{\mathrm{ms}}\right) \wedge\left(\mathrm{Lp}_{\mathrm{j}} \in \mathrm{G}\right)\right\}$

- Calculating the passive robustness margin associated to the set of subpaths $\varphi$,

- Removing the elementary monosynchronized subpath for the construction of the whole $\varphi^{*}$ defined as follows: $\varphi^{*}=\left\{\mathrm{Lp}_{\mathrm{j}} /\left(\mathrm{p}^{*} \in \mathrm{Lp}_{\mathrm{j}}\right) \wedge\left(\mathrm{Lp}_{\mathrm{j}} \in \mathrm{C}_{\mathrm{se}}\right) \wedge\left(\mathrm{Lp}_{\mathrm{j}} \in \mathrm{G}^{*}\right)\right\}$

- Computing, for each mono-synchronized subpath of $\varphi^{*}$, the passive robustness margin $\mathrm{F}$ defined as follows:

$\mathrm{F} \Leftarrow \min \left\{\min \left[\Delta \mathrm{rt},\left(\Delta \mathrm{rc}_{\mathrm{j}}+\mathrm{F}\left(\mathrm{G}^{*}\left(\mathrm{Lp}_{\mathrm{j}}, \mathrm{OUT}\left(\mathrm{Lp}_{\mathrm{j}}\right)^{\circ}, \min \left(\mathrm{b}_{\mathrm{i}}-\mathrm{q}_{\mathrm{ie}}\right)\right)\right)\right]\right\}\right.$ j $\quad \mathrm{p}_{\mathrm{i}}^{\mathrm{o}}=\operatorname{OUT}\left(\mathrm{Lp}_{\mathrm{j}}\right)$

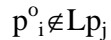

- Stopping the algorithm if the following condition is satisfied:

$$
\text { ( } \left.\varphi^{*}==\Phi \text { ou } \Delta \mathrm{rt}==0\right) \text { alors }(\mathrm{F} \Leftarrow \Delta \mathrm{rt})
$$

A. Algorithm 1 [Jerbi et al., 04]

Let us denote:

- $\mathrm{C}_{\mathrm{ms}}$ : the set of mono-synchronized subpaths,

- $\mathrm{C}_{\mathrm{se}}$ : the set of elementary monosynchronized subpaths,

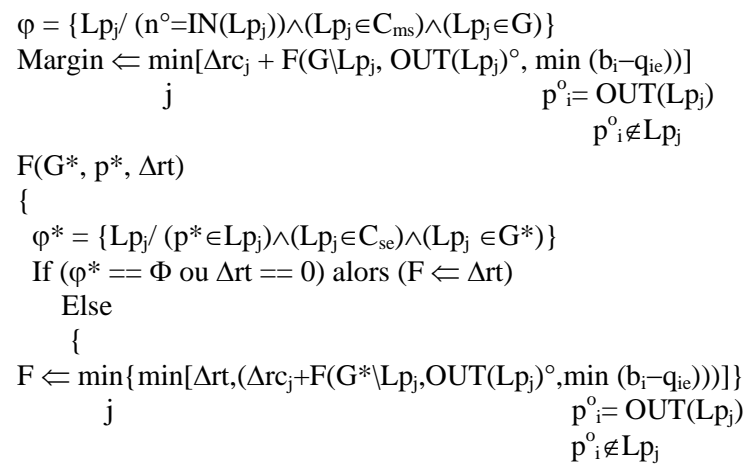

Note: When we remove a mono-synchronized subpath from $G$, this is only for the construction of $\varphi^{*}$. Places for which we seek mono-synchronized subpaths belong simply to 
G. Places adding some constraints on a synchronization transition are taken into account even if they belong to an eliminated mono synchronized subpath. So, the margin calculated by this algorithm is a lower bound of the effective margin.

\section{B. Application}

The application of algorithm 1 at the node $t_{9}$, Fig 3, allows computing a lower bound of passive robustness margin equal to 16 (Margin=16).

Let us verify the passive robustness margin on $t_{9}$ (lower bound of the robustness margin), computed by algorithm 1 . Let us take the Ptime Petri net example (Fig. 3).

Let $\delta=16$ a time disturbance in $\mathrm{p}_{9}$ (Hydromat) observed at $\mathrm{t}_{9}$. The disturbance $\delta$ is propagated towards the six paths $\mathrm{Lp}_{1}, \mathrm{Lp}_{2}, \mathrm{Lp}_{3}, \mathrm{Lp}_{4}, \mathrm{Lp}_{5}$ and $\mathrm{Lp}_{6}$ (see Table 1 ).

The algorithm proposed in [Jerbi et al, 04] is fair and fast, however there is no guarantee that this algorithm allows the avoidance of false alarms and the detection of constraints violation. Indeed the margin computed by this algorithm is a lower bound of the effective margin. This characteristic leads to a detection issue since it is not possible to prove that a real failure occurred when a disturbance exceeds the lower bound.

\subsubsection{Computation algorithm of the exact value of the passive robustness}

In order to avoid the violation of schedule conditions, a recursive algorithm allowing computing the exact maximal time disturbance allowed at a given point of the milk manufacturing workshop is presented. The purpose of this new algorithm is:

- to detect violation of constraints,

- to avoid false alarms, integrating the mutual compensation on different parallel paths

\section{A. Algorithm 2}

Let:

$\mathrm{L}=\underset{\mathrm{i}}{\cup} \mathrm{Lp} \mathrm{p}_{\mathrm{i}}$ : union of mono-synchronized subpaths

$\Delta \mathrm{rc}_{\mathrm{j}}$ : compensable margin on the monosynchronized subpath $\mathrm{Lp}_{\mathrm{j}}$

Res (L, Lp) : maximal residue of disturbance on $\operatorname{OUT}\left(\mathrm{Lp}_{\mathrm{i}}\right)$ (disturbance that propagates along parallel path $\mathrm{Lp}_{\mathrm{i}}$ )

(See scheme Algorithm 2)

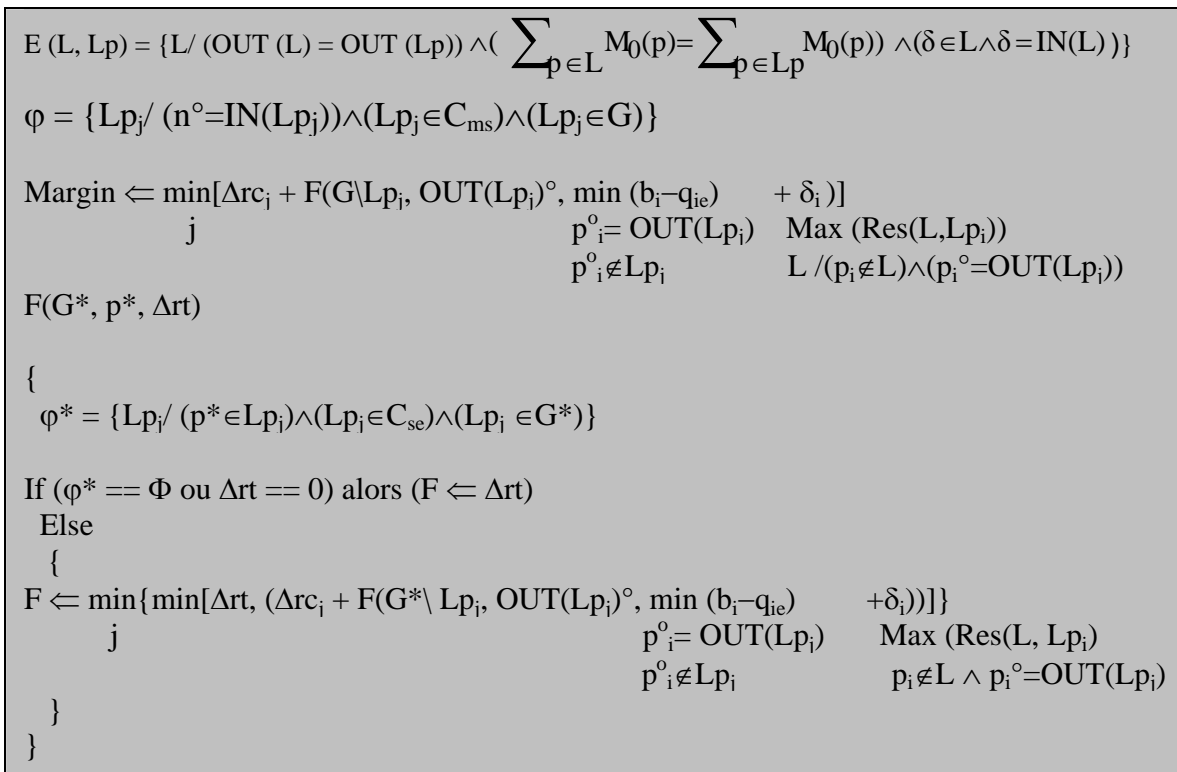

Algorithm 2 


\section{B. Illustrative example}

Let us take again the same example. The application of algorithm 2 at the node $t_{9}$, (see Figure 4), allows computing an upper bound of passive robustness margin; this example is a direct application of the algorithm. According to algorithm 2, the set of mono-synchronized subpaths $(\varphi)$ is defined as follows:

$\varphi=\left\{L p_{j} /\left(n^{\circ}=I N\left(L p_{j}\right)\right) \wedge\left(L p_{j} \in C_{m s}\right) \wedge\left(L p_{j} \in G\right)\right\}$

$\varphi=\left\{\mathbf{L p}_{0}=\left(\mathrm{p}_{9}, \mathrm{t}_{9}, \mathrm{p}_{18}, \mathrm{t}_{8}\right) ; \mathbf{L}_{\mathbf{1}}=\left(\mathrm{p}_{9}, \mathrm{t}_{9}, \mathrm{p}_{101}, \mathrm{t}_{101}\right) ; \mathbf{L}_{2}=\left(\mathrm{p}_{9}, \mathrm{t}_{9}\right.\right.$ $\left., \mathrm{p}_{102}, \mathrm{t}_{102}\right) ; \mathbf{L p}_{3}=\left(\mathrm{p}_{9}, \mathrm{t}_{9}, \mathrm{p}_{103}, \mathrm{t}_{103}\right) ; \mathbf{L}_{\mathbf{4}}=\left(\mathrm{p}_{9}, \mathrm{t}_{9}, \mathrm{p}_{104}, \mathrm{t}_{104}\right) ;$

$\left.\mathbf{L p}_{5}=\left(\mathrm{p}_{9}, \mathrm{t}_{9}, \mathrm{p}_{105}, \mathrm{t}_{105}\right) ; \mathbf{L p}_{6}=\left(\mathrm{p}_{9}, \mathrm{t}_{9}, \mathrm{p}_{106}, \mathrm{t}_{106}\right)\right\}$

The application of the algorithm at the node $t_{9}$, Fig. 4, allows computing an upper bound of passive robustness margin equal to 29 .

\section{Robustness result verification on the workshop}

This example allows verifying the passive robustness margin on $t_{9}$, computed by algorithm 2 (Margin=695).

Actually, there is a mutual compensation of parallel disturbances on paths $\mathrm{Lpi}$, with $i \in[1 . .6]$.

The disturbance restriction comes only from the tokens of places ${ }^{\circ} t_{78}$ (the set of input paces of the transition indexed by 78). Looking at Figure 2, the result seems trivial, but things are more difficult to understand on the transformed ordinary Petri net of Figure 4.

This particular example describes how the process passively rejects some time disturbances. Of course, there is no constraints violation, because the algorithm is only a recursive application of well known and proved robustness results [Chetouane et al. 2004], [Jerbi et al. 2007]. However, the robustness results were established on topologies with no assembling task. The extension of these results are allowed by a graph transformation inspired by the one presented by Nakamura [Nakamura and Silva, 1999].

\subsubsection{Comparative study}

The first bound proposed in 2004, allows eliminating some false alarms without big computation efforts. The above case study gives an idea of the bound performance with regard to the exact value.
The lower bound is 16, whereas the exact value is 695. It represents a variation of more than $400 \%$ !

It is not really surprising to find that a bound neglecting the effect of parallelisation provides poor results on assembling or packing topologies. Actually, this kind of workshop contains a lot of parallelisms and synchronization mechanisms.

The purpose of the newly proposed algorithm is the avoidance of false alarms. This allows minimizing the unjustified stops of production. A filtering mechanism of false alarms integrating the robustness values is claimed. This mechanism aims at generating symptoms for the diagnosis and allows avoiding production breakdowns when the time disturbance is in the robustness intervals.

Knowing the upper limit of passive robustness is really an improvement since it increases the system ability to maintain the production conditions. The use of this exact value improves the monitoring of the industrial processes with time constraints, increasing the productivity and reducing the maintenance costs by improving the availability of the production systems.

Based on this single real example, we can claim that the speed of the bound computation cannot justify its use in the general case. On the other hand, the new algorithm has to be studied from a computing complexity point of view in order to stand if it is really scalable.

\section{Conclusion}

After the transformation of the WMG associated to a milk manufacturing unit into an ordinary MG, the computation of the local passive robustness can be made. Two different algorithms computing respectively a lower and an exact value of the maximal time disturbance allowed at a given point are presented. The contribution of this paper is the algorithm computing the exact value of robustness margin.

The lower bound can be used in order to filter some alarms generated by the workshop during production [Jerbi et al., 06], [M'halla et al., 10 a]. Nevertheless, in some cases, it is not possible to say whether the behaviour of the system remains correct or not. Consequently, the filter eliminates some false alarms, but not 
all of them. Computing the exact value of the passive robustness is an important issue.

In order to solve the false alarm problem, a new algorithm is presented. This algorithm is applied for the computation of the maximal time disturbance allowed at a given point of the milk manufacturing workshop.

The results obtained in the illustrative example are very interesting: on the considered industrial example, the approximation introduced by using a bound is really not good. Consequently, a lot of false alarms may occur ensuing from this approximation.

The new algorithm considers the transmission of a disturbance on two parallel paths and allows computing the exact value of the passive robustness margin at various graph nodes. Moreover, an implementation on the whole system is possible. The scalability of the new algorithm still has to be studied, for example, from a computing complexity point of view. This next step is necessary, before saying that the newly presented algorithm has to replace the old one.

It is to be noted that the transformation from WMG to MG, used in this paper, allows applying robust control strategies facing disturbances in manufacturing workshops with assembling tasks as it was performed for workshop without assembling tasks. Some preliminary works have been presented [M'halla et al., $10 \mathrm{~b}$ ], but a global evaluation study of the dynamic control contribution still has to be made.

\section{REFERENCES}

1. CHETOUANE, F., S. COLLART DUTILLEUL, J.-P. DENAT, Modelling And Analysis of Time Constraints Using P-Time Petri Nets for a Multi-Hoist Electroplating Line, Conference IFAC/IFIP/IEEE Management and Control of Production and Logistics MCPL'04, Santiago, Chile, Nov. 2004, pp. 279-284.

2. COLLART-DUTILLEUL, S., N. JERBI, E. CRAYE, M. BENREJEB, Robust Dynamic Control of Multi-product Jobshops, 4th IFAC Conference on Management and Control of Production and Logistics, MCPL'07, Sibiu, Vol. 2, 2007, pp. $265-270$.
3. COMMONER F., A. W. HOLT, S. EVEN, A. PNUELI, Marked Directed Graphs, Journal of Computer and System Sciences, Vol. 5, 1971, pp. 511-523.

4. HAMACI, S., J.-L. BOIMOND, S. LAHAYE, Performance Analysis of Timed Event Graphs with Multipliers using (Min, +) Algebra, Journal of Discret Event System, Vol. 16, 2006, pp. 185-190.

5. JERBI, N., S. COLLART DUTILLEUL, E. CRAYE, M. BENREJEB, Robust Control of Multi-product Job-shops in Repetitive Functioning Mode, IEEE International Conference on Systems, Man and Cybernetic, 2004, pp. 4917-4922.

6. JERBI N., S. COLLART DUTILLEUL, E. CRAYE, M. BENREJEB, Time Disturbances and Filtering of Sensors Signals in Tolerant Multi-product Jobshops with Time Constraints, International Journal of Computers, Communications \& Control, Vol. 1, No. 4, 2006, pp. $61-72$.

7. JERBI N., S. COLLART DUTILLEUL, E. CRAYE, M. BENREJEB, Localization Algorithm of Time Disturbances in Tolerant Multi-product Job-shops, Studies in Informatics Control, Vol. 16, $\mathrm{N}^{\circ} 1,2007$.

8. JERBI N., S. COLLART-DUTILLEUL, E. CRAYE, M. BENREJEB, Commande robuste des ateliers manufacturiers à contraintes de temps, Journal Européen des Systèmes Automatisés, Vol. 43, No. 12, 2009, pp. 7-33.

9. KHANSA, W., J. P. DENAT, S. COLlart-DUTILleul, P-Time Petri Nets for Manufacturing Systems, IEE Workshop on Discrete Event Systems (WODES'96), Edinburgh, 1996, pp. 94-102.

10. LONG, J., Flow Optimization Method for Control Synthesis of Flexible Manufacturing Systems Modeled by Controlled Timed Petri Nets, IEEE International Conference on Robotics and Automation, Atlanta, Vol. 1, 1993, pp. $598-603$.

11. MARCHETTI, O., A. MUNIER, A Sufficient Condition for the Liveness of Weighted Event Graphs, European 
Journal of Operational Research, Vol. 197, Issue 2, 2009, pp. 532-540.

12. M'HALLA, A., N. JERBI, S. COLLARTDUTILLEUL, CRAYE E., M. BENREJEB, Fuzzy Filtering of Sensors Signals in Manufacturing Systems with Time Constraints, International Journal of Computers, Communications \& Control, Vol. 5, Issue 3, 2010.

13. M'HALLA, A., N. JERBI, S. COLLARTDUTILLEUL, CRAYE E., M. BENREJEB, Rejection of Temporal Disturbances in Milk Manufacturing Unit with Time Constraints, CD-Rom of IFAC Symposium on Large Scale Systems: Theory and Applications, LSS 2010, France.

14. M'HALLA, A., N. JERBI, S. COLLARTDUTILLEUL, CRAYE E., M. BENREJEB, Passive Robustness in Milk Manufacturing Unit with Time Constraints, in USB key proceeding of International Conference on Management and Control of Production and Logistics MCPL 2010, Portugal.

15. M'HALLA, A., N. JERBI, S. COLLARTDUTILLEUL, CRAYE E., M. BENREJEB, Graphe d'événement $\mathbf{P}$ Temporel à Arc valués : Application à une Unité de Production du Lait. Revue Electronique Sciences \& Technologies de l'Automatique (e-STA), Vol. 7, nº 1, 2010, pp. 9-16.
16. MUNIER, A., Régime asymptotique optimal d'un graphe d'événements temporisé: application à un problème d'assemblage, RAIRO 27(5), 1993, pp. 171-180.

17. NAKAMURA, M., M. SILVA, Cycle Time Computation in Deterministically Timed Weighted Marked Graphs, 7th IEEE International Conference on Emerging Technologies and Factory Automation, Vol.2, Spain, 1999, pp. 1037-1046.

18. TOURSI L., N. SAUER, Branch and Bound Approach for Marking Optimization Problem of Weighted Marked Graphs, IEEE International Conference on Systems, Man and Cybernetic, The Hague, Vol. 2, 2004, pp. 1777-1782.

19. TERUEL E., P. CHRZASTOWSKIWACHTEL, J. M. COLOM, M. SILVA, On weighted T-systems, Advances in Petri nets, Lecture Notes in Computer Science, Vol. 616, 1992, pp. 348-367.

20. SAUER N., Marking Optimization of Weighted Marked Graphs, Journal of Discrete Event Dynamic Systems: Theory and Applications, Vol. 13, Issue 3, 2003, pp. 245-262. 